\title{
The paradox of surgical management of patients with low-flow, low-gradient aortic stenosis
}

\author{
Vinay Badhwar, MD, ${ }^{\mathrm{a}}$ John S. Ikonomidis, MD, PhD, ${ }^{\mathrm{b}}$ and Jeffrey P. Jacobs, MD
}

See related article on pages $1558-66$.

In this issue of the Journal, Parikh and colleagues ${ }^{1}$ elegantly analyze the institutional outcomes of aortic valve replacement (AVR) at the Cleveland Clinic to illustrate the potential impact of low-flow, low-gradient aortic stenosis (LFLGAS) on 5-year post-AVR mortality. Despite quite acceptable initial operative outcomes, a fifth of their 875 consecutive patients who underwent surgical AVR for severe stenosis during a 2-year period were dead at 5 years. Preoperative left ventricular stroke volume index (LVSVI) was used to identify both LFLGAS with low ejection fraction (EF) and paradoxic LFLGAS with an EF of 50\% or greater. It was determined that either variant of LFLGAS independently predicted early mortality.

The natural history of LFLGAS with low EF and paradoxic LFLGAS has long been linked to mortality, yet its diagnosis and management remain challenging. ${ }^{2-4}$ Parikh and colleagues ${ }^{1}$ laudably applied rigorous echocardiographic standards and measured the LVSVI for additional clarity in their diagnosis of LFLGAS, consistent with current guidelines. ${ }^{2}$ The standards used in this study, however, may not necessarily be reproducible in all centers for the reliable diagnosis of LFLGAS. The echocardiographic assessment of valve area by the continuity equation involves an estimation of flow on the basis of an assumption of left ventricular outflow tract circularity. Variability of outflow tract anatomy and Doppler angle placement may commonly impair precise echocardiographic assessment of flow and of calculated valve area. ${ }^{3,4}$ In the setting of LFLGAS and low EF, adjunctive catheterization or dobutamine testing is often used to differentiate true valve severity from a state of low output and only moderate aortic stenosis. ${ }^{5}$ Furthermore, the diagnosis of paradoxic LFLGAS may be confounded by multiple factors, such as

\footnotetext{
From the Department of Cardiothoracic Surgery, ${ }^{\text {a }}$ University of Pittsburgh, Pittsburgh, Pa; the Division of Cardiothoracic Surgery, ${ }^{\mathrm{b}}$ Medical University of South Carolina, Charleston, SC; and the Division of Cardiothoracic Surgery, ${ }^{\mathrm{c}}$ Johns Hopkins All Children's Heart Institute, St Petersburg, Fla.

Disclosures: Authors have nothing to disclose with regard to commercial support.

Received for publication March 16, 2015; accepted for publication March 16, 2015; available ahead of print April 11, 2015.

Address for reprints: Vinay Badhwar, MD, Department of Cardiothoracic Surgery, University of Pittsburgh, 200 Lothrop St, C-724, Pittsburgh, PA 15213 (E-mail: badhwarv@upmc.edu).

J Thorac Cardiovasc Surg 2015;149:1481-2

$0022-5223 / \$ 36.00$

Copyright (C) 2015 by The American Association for Thoracic Surgery http://dx.doi.org/10.1016/j.jtcvs.2015.03.024
}

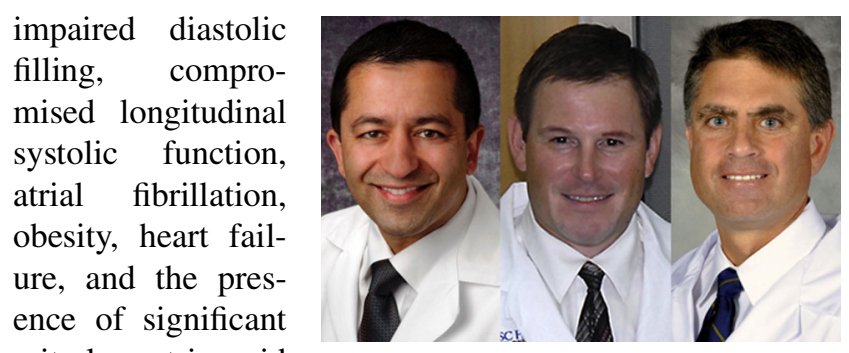
mitral or tricuspid valve regurgitation or stenosis. ${ }^{3,6}$ In response, some have advocated the use of cardiac magnetic resonance imaging as a more precise diagnostic tool that may simultaneously detect potential outcome-influencing myocardial fibrosis. ${ }^{4,7}$ Nevertheless, when accurately diagnosed, LFLGAS is a known marker of reduced survival. ${ }^{2-7}$

Parikh and colleagues ${ }^{1}$ clearly demonstrate that LVSVI and the subtype of aortic stenosis have an influence on 5year mortality after AVR. They note that for paradoxic LFLGAS the hazard ratio was 1.48 (95\% confidence interval [CI] of 1.15-1.88), whereas LFLGAS with low EF had a hazard ratio of 2.03 (95\% CI of 1.41-2.93). It is of comparative interest that their univariable hazard ratios associated with preoperative dialysis and reoperative cardiac surgery were 3.97 (95\% CI of 2.12-7.43) and 2.07 (95\% CI of 1.48-2.92), respectively. In a recent similar analysis of 1154 patients undergoing AVR, Clavel and associates ${ }^{8}$ also found that LVSVI was an important preoperative predictor of mortality and that both LFLGAS subtypes were associated with a higher risk of operative mortality. In contrast to the current study of Parikh and colleagues, ${ }^{1}$ however, the 5-year survivorship of patients with paradoxic LFLGAS was equal to that of those with standard aortic stenosis when EF was normal, and only patients with both LFLGAS and low EF had higher midterm mortality. Both studies attest that LFLGAS is a marker of late disease warranting earlier referral for AVR. Moreover, both studies note that LVSVI is an independent predictor of outcome that could potentially enhance the existing Society of Thoracic Surgeons risk models. Both investigative teams therefore advocate in favor of the integration of LVSVI into risk models for AVR.

Comprehensive risk adjustment inclusive of preoperative factors and case mix is essential for any predictive model of outcome in cardiac surgery. The Society of Thoracic Surgeons has developed such risk models for isolated AVR, with and without coronary artery bypass grafting, on the basis of a database including more than 100,000 patients that is now used in the assessment of performance and the 
transparent public reporting of outcomes. ${ }^{9,10}$ The selection of variables used in any risk model requires a careful balance of statistical methodologies and clinical realities. Clearly, the most accurate models would contain every relevant piece of patient data. The challenge, however, is one of consistent data capture. Elements of data that are ultimately selected for a risk model must meet 2 important criteria. First, these elements must be consistently associated with outcome, and second, they must be suitable for consistent capture in a multiinstitutional registry. For example, most would agree that age is associated with outcome and it can be captured consistently across institutions. Conversely, most would also now agree that a measure of frailty has important outcome implications in cardiac surgery; however, frailty is particularly difficult to capture consistently in a multi-institutional registry. We fully agree with Parikh and colleagues ${ }^{1}$ that LVSVI is an important predictor of AVR outcome, but it remains to be determined whether the LVSVI can be both determined consistently and captured consistently in a multi-institutional registry.

Despite the accurate diagnosis of paradoxic or low-EF LFLGAS, recent comparative evidence reveals that longitudinal surgical and even transcatheter AVR outcomes remain superior to those of conservative medical management. ${ }^{8,11}$ Although Parikh and colleagues ${ }^{1}$ have further clarified the serious impact of low flow on AVR outcome, it will likely only be through further randomized or registry evidence that we will be able to ascertain whether there are specific procedures or prostheses that could further benefit this high-risk cohort. For now, it appears the answer to the paradox of surgical management in LFLGAS is to proceed with prejudice.

\section{References}

1. Parikh R, Goodman AL, Barr T, Sabik JF, Svensson LG, Rodriguez LL, et al Outcomes of surgical aortic valve replacement for severe aortic stenosis: incor poration of left ventricular systolic function and stroke volume index. $J$ Thorac Cardiovasc Surg. 2015;149:1558-66.e1.

2. Nishimura RA, Otto CM, Bonow RO, Carabello BA, Erwin JP III, Guyton RA, et al; American College of Cardiology; American College of Cardiology/ American Heart Association; American Heart Association. 2014 AHA/ACC guideline for the management of patients with valvular heart disease: a report of the American College of Cardiology/American Heart Association Task Force on Practice Guidelines. J Thorac Cardiovasc Surg. 2014;148:e1-132. Erratum in: J Thorac Cardiovasc Surg. 2014;64:1763.

3. Pibarot P, Dumesnil JG. Paradoxical low-flow, low-gradient aortic stenosis: new evidence, more questions. Circulation. 2013;128:1729-32.

4. Barone-Rochette G, Piérard S, Seldrum S, de Meester de Ravenstein C, Melchior J, Maes F, et al. Aortic valve area, stroke volume, left ventricular hypertrophy, remodeling, and fibrosis in aortic stenosis assessed by cardiac magnetic resonance imaging: comparison between high and low gradient and normal and low flow aortic stenosis. Circ Cardiovasc Imaging. 2013;6:1009-17.

5. Nishimura RA, Grantham JA, Connolly HM, Schaff HV, Higano ST, Holmes DR Jr. Low-output, low-gradient aortic stenosis in patients with depressed left ventricular systolic function: the clinical utility of the dobutamine challenge in the catheterization laboratory. Circulation. 2002;106:809-13.

6. Eleid MF, Sorajja P, Michelena HI, Malouf JF, Scott CG, Pellikka PA. Flowgradient patterns in severe aortic stenosis with preserved ejection fraction: clinical characteristics and predictors of survival. Circulation. 2013;128: 1781-9.

7. Barone-Rochette G, Piérard S, De Meester de Ravenstein C, Seldrum S, Melchior J, Maes F, et al. Prognostic significance of LGE by CMR in aortic stenosis patients undergoing valve replacement. JAm Coll Cardiol. 2014;64:144-54.

8. Clavel MA, Berthelot-Richer M, Le Ven F, Capoulade R, Dahou A, Dumesnil JG, et al. Impact of classic and paradoxical low flow on survival after aortic valve replacement for severe aortic stenosis. J Am Coll Cardiol. 2015;65: 645-53.

9. Shahian DM, He X, Jacobs JP, Rankin JS, Welke KF, Filardo G, et al. The Society of Thoracic Surgeons Isolated Aortic Valve Replacement (AVR) Composite Score: a report of the STS Quality Measurement Task Force. Ann Thorac Surg. 2012;94:2166-71

10. Shahian DM, He X, Jacobs JP, Rankin JS, Welke KF, Edwards FH, et al. The STS AVR + CABG composite score: a report of the STS Quality Measurement Task Force. Ann Thorac Surg. 2014;97:1604-9.

11. Grupper A, Beigel R, Maor E, Kuperstein R, Hai I, Perelshtein O, et al. Survival following intervention in patients with low gradient severe aortic stenosis and preserved left ventricle function. J Thorac Cardiovasc Surg. 2014;148: 2823-8. 